\title{
Functions of the CXCL12 Receptor ACKR3/CXCR7-What Has Been Perceived and What Has Been Overlooked
}

\author{
Christian Koch and Jürgen Engele \\ Institute of Anatomy, University of Leipzig, Medical Faculty, Leipzig, Germany \\ Received May 5, 2020; accepted July 31, 2020
}

\section{ABSTRACT}

The CXCL12 system is central to the development of many organs and is further crucially engaged in pathophysiological processes underlying cancer, inflammation, and cardiovascular disorders. This disease-associated role presently focuses major interest on the two CXCL12 receptors, CXCR4 and atypical chemokine receptor 3 (ACKR3)/CXCR7, as promising therapeutic targets. Major obstacles in these ongoing efforts are confusing reports on the differential use of either ACKR3/CXCR7 and/or CXCR4 across various cells as well as on the specific function(s) of ACKR3/CXCR7. Although basically no doubts remain that CXCR4 represents a classic chemokine receptor, functions assigned to ACKR3/CXCR7 range from those of a strictly silent scavenger receptor eventually modulating CXCR4 signaling to an active and independent signaling receptor. In this review, we depict a thorough analysis of our present knowledge on different modes of organization and functions of the cellular CXCL12 system. We further highlight the potential role of ACKR3/ CXCR7 as a "crosslinker" of different receptor systems. Finally, we discuss mechanisms with the potency to impinge on the cellular organization of the CXCL12 system and hence might represent additional future therapeutic targets.

\section{SIGNIFICANCE STATEMENT}

Delineating the recognized functions of atypical chemokine receptor 3 and CXCR4 in CXCL12 signaling is central to the more detailed understanding of the role of the CXCL12 system in health and disease and will help to guide future research efforts.

\section{Introduction}

A prominent feature of most chemokines and chemokine receptors is their high promiscuity, meaning that a given chemokine generally binds several chemokine receptors, and, vice versa, a given chemokine receptor binds several chemokines. This polygamous feature most likely reflects the evolutionary necessity to generate rapid and powerful host immune responses (Zlotnik and Yoshie 2012). A long-held exemption from this rule was CXCL12 (stromal cell-derived factor 1), which was assumed to solely interact with CXCR4. CXCR4 represents a classic GPCR that preferentially binds $\mathrm{G} \alpha_{\mathrm{i}}$ but also $\mathrm{G} \alpha_{\mathrm{q}}$ and $\mathrm{G} \alpha_{12 / 13}$ (Heuninck et al., 2019, for review), subsequently allowing for the activation of various signaling pathways/cascades (Mousavi, 2020, for a recent review). It has been further claimed that CXCR4 would additionally activate arrestin-dependent signaling [see Rigo et al. (2018) for a recent work]. Notably, arrestins primarily represent adaptor proteins essential for desensitization and endocytosis of GPCRs. In addition, arrestins can allow for

This work did not receive any specific grant from funding agencies in the public, commercial, or not-for-profit sectors. There are no financial conflicts of interest to disclose.

https://doi.org/10.1124/molpharm.120.000056. receptor signaling from endosomes by acting as scaffold proteins (Thomsen et al., 2018, for review). As a consequence of this manifold, knockout of arrestins was found to result in signal amplification, deletion, or partial alteration of downstream signaling pathways (Luttrell et al., 2018). These remarkably divergent functions of the arrestin family seem to correlate with distinct binding sites at the GPCR, referred to as the C-terminal "tail" or the transmembranous "core" conformation (Cahill et al., 2017). Whereas previous work convincingly demonstrated that ligand-activated CXCR4 recruits $\beta$-arrestin preferentially to its $\mathrm{C}$ terminus (Luo et al., 2017), none of the available studies presented unequivocal evidence for arrestin-dependent signaling of CXCR4 by ruling out the potential involvement of other (dimerizing) receptor proteins.

The aforementioned intimacy between CXCL12 and CXCR4 ceased with the demonstration of CXCR7 as a second CXCL12 receptor (Balabanian et al., 2005; Burns et al., 2006). CXCR7 binds CXCL12 with distinctly higher affinity when compared with CXCR4 $\left(\mathrm{K}_{\mathrm{d}}=0.4 \mathrm{nM}\right.$ vs. $\left.3.6 \mathrm{nM}\right)$ and uses CXCL11, macrophage inhibitory factor (MIF), adrenomedullin (ADM), opioid peptides, and the viral chemokine vCCL2/viral macrophage inflammatory protein-II as additional ligands (Wang et al., 2018a; Meyrath et al., 2020; Perpina-Viciano et al., 2020 
for review). In 2014, the Nomenclature and Standards Committee of the International Union of Basic and Clinical Pharmacology subcommittee for the chemokine receptors considered CXCR7 as an atypical chemokine receptor and renamed it to atypical chemokine receptor 3 (ACKR3) (Bachelerie et al., 2014). This step was spurred by several findings and observations:

1. ACKR3 exhibits an altered DRYLAIV motif (DRYLSIT) in the second intracellular loop, which is assumed to be essential for binding and activation of G proteins. It is, however, noteworthy that this dogma was challenged by the findings that alterations of the DRY motif within XCR1 and CXCR6 - both considered as classic chemokine receptors-do not preclude activation of $\mathrm{G}$ proteins and induction of cell migration (Chandrasekar et al., 2004; Fox et al., 2019).

2. In several cell lines, such as CHO, MLE-12, CNE 2Z, and MCF-7 cells as well as primary vascular smooth muscle cells, ACKR3 does not induce calcium flux, which is considered as an indication that ACKR3 fails to activate G proteins (Burns et al., 2006; Rajagopal et al., 2010; Qiao et al., 2016; Chang et al., 2018; Del Molino Del Barrio et al., 2018). A single study demonstrated binding of $\mathrm{G}_{\alpha \mathrm{I}}$ to ACKR3 in HEK-293T cells by bioluminescence resonance energy transfer analysis, which, again, does not allow for $\mathrm{Ca}^{2+}$ responses (Levoye et al., 2009). Presently, the only known exceptions from this rule are primary astrocytes and distinct glioma cell(s) (lines). These cells respond to CXCL12-dependent activation of ACKR3 with increases in intracellular $\mathrm{Ca}^{2+}$, which can be reversed by pertussis toxin (Ödemis et al., 2012). Evidence that observed $\mathrm{Ca}^{2+}$ responses are in fact directly linked to ACKR3 are further given by the observation that $\mathrm{Ca}^{2+}$ increases likewise occur in $\mathrm{CXCR} 4^{-/-}$astrocytes as well as glioma cells not harboring CXCR4 (Ödemis et al., 2012). It is noteworthy that disparate findings have been previously obtained with human glioblastoma U87 cells in which CXCR4 or CXCR7 was stably overexpressed (Doijen et al., 2017).

3. Finally, several groups established that ACKR3 acts as a scavenger of extracellular CXCL12 (and CXCL11) by constantly cycling between the plasma membrane and intracellular structures and hereby establishing a CXCL12 gradient (Koenen et al., 2019, for review). According to a recent study, the equilibrium between intracellular and membrane-bound ACKR3, and thus scavenging function, is tightly regulated by CXCL12induced phosphorylation of the receptor protein and its subsequent protection from degradation (Lau et al., 2020).

These atypical functions, however, do not necessarily mean that ACKR3 represents a strictly silent CXCL12 receptor. In fact, an exhaustive body of literature shows active signaling of ACKR3 (see Tables 1 and 3), which is thought to depend on arrestin. This assumption is primarily based on the demonstration that ligand-dependent activation of CXCR7 results in the recruitment of arrestin to the receptor protein, which is followed by endocytosis and the activation of signaling pathways (Luker et al., 2009; Rajagopal et al., 2010). Furthermore, CXCR7 signaling is attenuated or prevented after either cellular arrestin depletion or truncation of the CXCR7 C terminus (Xu et al., 2019; Min et al., 2020). In addition to the direct activation of signaling proteins/pathways by ACKR3 within the arrestin scaffold, indirect modes of activation seem to exist and involve the Src kinase- and/or arrestin-dependent transactivation of epidermal growth factor receptor (McGinn et al., 2012; Salazar et al., 2014; Xu et al., 2019). Notably, the concept of arrestin-dependent signaling of ACKR3 was recently challenged by the demonstration that arrestins fail to drive extracellular signal-regulated kinases (ERK) phosphorylation in the presence of fully inactivated $G$ proteins (Grundmann et al., 2018). Moreover, within endosome arrestins, GPCRs, and G proteins can form so-called supercomplexes, which allow for sustained GPCR signaling (Thomsen et al., 2016). However, whether arrestins show similar interactions with (typical and/or atypical) chemokine receptors still needs to be seen.

As discussed in depth in the following chapters, signaling of CXCR4 and CXCR7 gets further complicated by formation of dimers/oligomers with other GPCRs or non-GPCRs. Special attention attracted the dimerization of CXCR4 with CXCR7 and resulting consequences for cell signaling (see following chapters). The formation of CXCR4/CXCR7 heteromers was previously demonstrated by bioluminescence resonance energy transfer (Levoye et al., 2009), fluorescence resonance energy transfer (Del Molino Del Barrio et al., 2018), protein fragment complementation assay (Luker et al., 2009), and proximity ligation assay (Evans et al., 2016; Albee et al., 2017). Notably, only proximity ligation assay allows the demonstration of heterodimerization of native receptors, whereas the other experimental approaches require the previous ectopic expression of appropriate tagged receptor proteins, which might behave differently. At present, effects of receptor heteromerization on cell signaling have only been characterized in cells with either receptor overexpression or inhibited receptor expression and hence altered levels of total cellular receptor proteins, which could very well bias "normal" CXCL12signaling. An experimental approach not biased by receptor expression levels would include the possibility to interfere with the heteromerization process of CXCL12 receptors. Unfortunately, respective tools, such as synthetic peptides preventing receptor heterodimerization, are currently missing or lack sufficient efficacy (Evans et al., 2016).

On July 24, 2020, the search term "CXCL12" retrieved 292 original publications for 2020 in PubMed. In almost $80 \%$ of these publications, there is no mentioning of "ACKR3" or "CXCR7." This shortfall reflects the still prevailing ignorance of ACKR3 as an active signaling receptor and spotlights the urgent need for the better awareness of the central role of ACKR3 in CXCL12 signaling. Recent review articles, which appeared in this journal, already give a comprehensive overview of the mechanistic base of CXCR4 and CXCR7 signaling and its principal modulation by receptor heteromerization/ oligomerization, alternative ligands, and subcellular localization of receptors (Fumagalli et al., 2019; Heuninck et al., 2019; Koenen et al., 2019). The present review intends to complete the picture by defining how CXCR4 and ACKR3 are actually involved in CXCL12 signaling across cells. We start with an overview of the documented atypical functions of ACKR3. We then continue with a first-time compilation of recognized molecular modes of cellular CXCL12 signaling and further discuss potential mechanisms involved in sculpting 
TABLE 1

Studies having identified the CXCL12 receptor mediating distinct CXCL12 responses

Only studies in which the involvement of the respective other CXCL12 receptor has been experimentally excluded are listed.

\begin{tabular}{|c|c|c|c|}
\hline Cell Type & Cell Function & $\begin{array}{l}\text { CXCL12 } \\
\text { Receptor }\end{array}$ & Reference \\
\hline Mouse M1 macrophages & Migration & ACKR3 & Zhang et al., 2020 \\
\hline Human pulmonary adenocarcinoma cell line (A549) & Migration & ACKR3 & $\begin{array}{l}\text { Choi et al., 2014; } \\
\quad \text { Puchert et al., } 2018\end{array}$ \\
\hline Human colorectal adenocarcinoma cell line (DLD-1) & Migration & ACKR3 & Puchert et al., 2018 \\
\hline $\begin{array}{l}\text { Human breast adenocarcinoma cell line } \\
\text { (MDA-MB-231) }\end{array}$ & Proliferation & CXCR4 & Puchert et al., 2018 \\
\hline Human prostate adenocarcinoma cell line (PC-3) & Proliferation & CXCR4 & Puchert et al., 2018 \\
\hline Human decidual epithelial cells & Migration & CXCR4 & Zheng et al., 2018 \\
\hline Mouse neural progenitor cells & Proliferation & ACKR3 & Wang et al., 2016 \\
\hline $\begin{array}{l}\text { Human acute myeloid leukemia cell lines } \\
\text { (MO7e, U937) }\end{array}$ & Migration & CXCR4 & Kim et al., 2015 \\
\hline Human nonsmall cell lung cancer cells & $\begin{array}{l}\text { Migration, transendothelial } \\
\text { migration }\end{array}$ & CXCR4 & Choi et al., 2014 \\
\hline Bovine aortic endothelial cells & $\begin{array}{l}\text { Transendothelial electrical } \\
\text { resistance (endothelial } \\
\text { barrier enhancement) }\end{array}$ & CXCR4 & Kobayashi et al., 2014 \\
\hline Rhesus macaque chorioretinal cells $(\mathrm{RF} / 6 \mathrm{~A})$ & Migration, proliferation & CXCR4 & Jin et al., 2013 \\
\hline Human glioblastoma-derived endothelial cells & Tube formation & CXCR4 & Liu et al., 2013a \\
\hline Human macrophages & Phagocytic activity & ACKR3 & Ma et al., 2013 \\
\hline Human melanocytes & Migration & ACKR3 & Lee et al., 2013 \\
\hline Rat primary cortical astrocytes & Proliferation, migration & ACKR3 & Ödemis et al., 2010, 2012 \\
\hline Human Burkitt's lymphoma cell line (NC-37) & Transendothelial migration & ACKR3 & Zabel et al., 2011 \\
\hline
\end{tabular}

the CXCL12 system across cells and how ACKR3 might additionally link different receptor systems.

\section{Atypical Functions of ACKR3-ACKR3 as a CXCL12 Scavenger}

The (atypical) function of ACKR3 as a CXCL12 scavenger is central to the development of many organs and is crucial to the control and coordination of cell migration and positioning (Quinn et al., 2018, for review). Importantly, these atypical functions do not solely depend on ACKR3 but require an intimate interplay between CXCL12, CXCR4, and ACKR3. As experimentally established in the zebrafish, ACKR3 enables CXCR4-dependent cell migration by continuous sequestration of CXCL12 and the subsequent formation of a CXCL12 gradient (see, for example, Dona et al., 2013). Interestingly, ACKR3 adjusts the CXCL12 gradient close to the dissociation constant of CXCR4 and thus ensures the optimal directional signal (Lau et al., 2020). Reflecting the crucial role of CXCL12 scavenging in many developmental processes, both ACKR3 mRNA and protein levels are high in embryonic organs/anlagen and decline into adulthood (Koenen et al., 2019, for review; Puchert et al., 2017). Nevertheless, low levels of ACKR3 in mature endothelial cells seem to be sufficient to form a sink, allowing the modulation of CXCL12 plasma levels and, hence, tissue homeostasis (Berahovich et al., 2014). Along with ACKR3dependent clearance of extracellular CXCL12, ACKR3 affects expression levels of CXCR4 by preventing its ligandinduced internalization and subsequent degradation, a mechanism essential to the formation of glomerular tufts in developing kidneys as well as during migration of interneurons (Sánchez-Alcañiz et al., 2011; Haege et al., 2012). Importantly, the scavenging function of ACKR3 is not limited to physiologic processes but seems to be also active under pathologic conditions. Indeed, studies using a mouse xenograft model of human breast cancer identified an intratumoral subpopulation of $\mathrm{ACKR}^{+}$cells, which by sequestering CXCL12 favors proliferation of a subpopulation of $\mathrm{CXCR}^{+}{ }^{+}$cancer cells (Luker et al., 2012).

\section{Is Suppression of CXCR4 Signaling Another Atypical Function of ACKR3?}

Soon after the identification of ACKR3 as a second CXCL12 receptor, it was claimed that ACKR3 might suppress or dampen CXCR4 signaling by forming ACKR3/CXCR4 heterodimers (Levoye et al., 2009; Fig. 1A). This claim was based on the demonstration that transient or stable overexpression of the receptor protein in HEK-293T cells attenuates CXCR4induced rises in intracellular $\mathrm{Ca}^{2+}$. More recently, a similar impairment of CXCR4 signaling was seen after ectopic overexpression of ACKR3 in U87 human glioma cells (Doijen et al., 2017). Despite these findings, it still remains questionable whether such suppressive effects are a general feature of ACKR3 and would also apply for endogenous ACKR3. A pathophysiological condition typically associated with increased expression of (endogenous) CXCL12 and its receptors is hypoxia. Most intriguingly, hypoxia-induced increases of ACKR3 in primary hippocampal progenitor cells do not attenuate but rather promote CXCL12-dependent chemotaxis, which is an effect reversed by ACKR3 short hairpin RNA interference (Liu et al., 2013b). A similar correlation between hypoxia-induced expression of ACKR3 and increased chemotactic responses was shown for several other types of cells, including renal cell carcinoma cell lines and colon cancer cells (Romain et al., 2014; Zhang et al., 2016). Although not all of the potentiating effects of hypoxia seen with the various cell(s)/lines might be attributed to enhanced expression of ACKR3 but could also be due to the increased expression of CXCR4, an issue not tested in most studies, it is obvious that increases in endogenous ACKR3 do not necessarily dampen CXCR4 signaling. Nevertheless, few examples exist in which depletion of endogenous ACKR3 seems to enhance CXCR4 
A
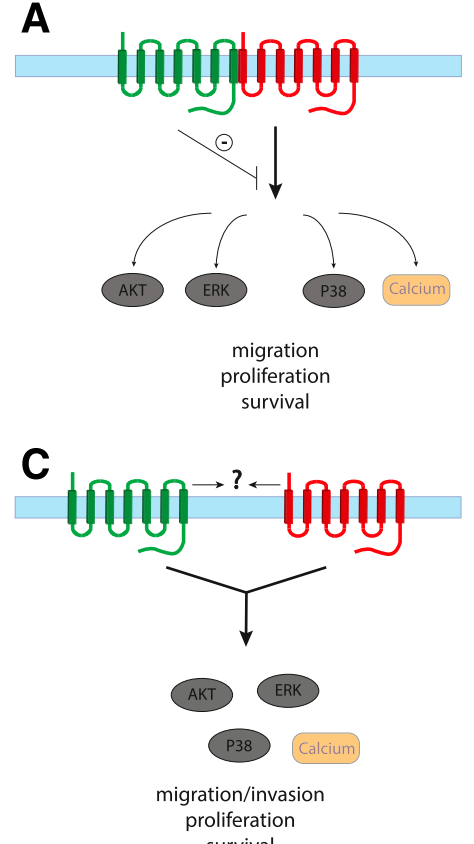
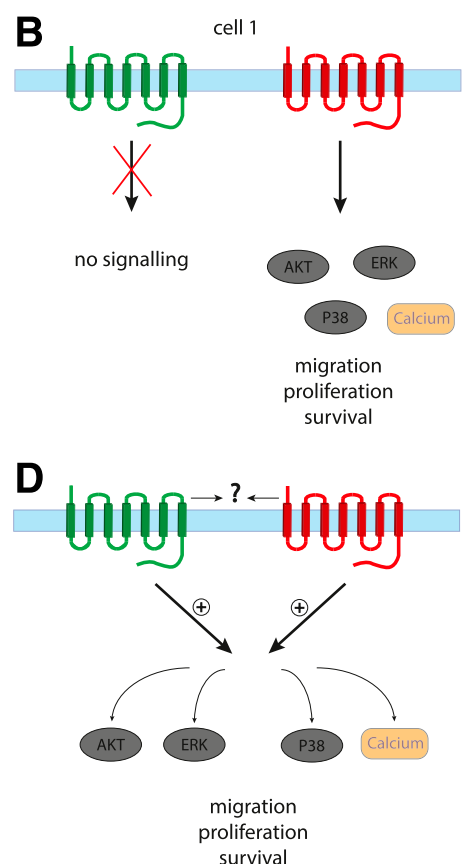
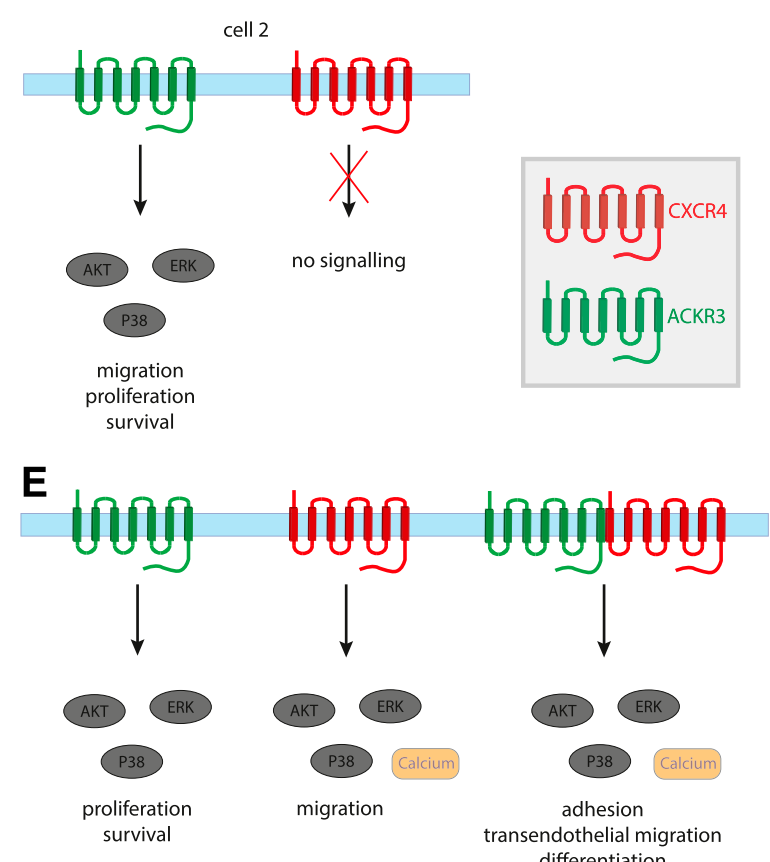

differentiation

Fig. 1. Perceived possibilities of how ACKR3 and CXCR4 are involved in CXCL12 signaling. A detailed description of the various types of interaction is given in the text. (A) ACKR3 dampens CXCR4 signaling by forming ACKR3/CXCR4 heterodimers. This interaction was originally described in cells ectopically overexpressing CXCR7 but has been rarely seen with endogenous CXCR7. (B) As shown for numerous different cell types, a distinct cell function (e.g., migration, proliferation, etc.) is either controlled by ACKR3 or CXCR4. (C) Many examples exist in which CXCR4 and ACKR3 act synergistically, in terms of that cellular effects of CXCL12 only occur when both receptors are present. Whether such synergistic effects depend on receptor heterodimerization is still unknown. (D) In addition to synergistic effects, few studies demonstrated additive effects of ACKR3 and CXCR4 on a given cell function. Whether additive effects require receptor heterodimerization has, again, not yet been tested experimentally. (E) Within a given cell type, CXCR4, ACKR3, and CXCR4/ACKR3 heterodimers control distinctly different cell functions. This seems to be the typical organization of the CXCL12 system in many types of stem and progenitor cells.

function. In nasopharyngeal carcinoma cells, in which ACKR3 expression is inhibited by RNA interference, CXCL12 induces a more rapid and slightly higher $\mathrm{Ca}^{2+}$ response when compared with wild-type cells (Qiao et al., 2016). Similarly, knockdown of ACKR3 in the human prostate cancer cell line LNCaP enhances chemotactic responses to CXCL12 (Yu et al., 2020).

\section{Active Functions of ACKR3-Cell-Specific Use of ACKR3 and CXCR4 to Control Distinct Cell Functions}

It is now indisputable that ACKR3 is capable of actively controlling the very same cell functions as CXCR4, including cell migration (chemotaxis)/transendothelial migration and cell proliferation (see Table 1). Notwithstanding the still ongoing dispute on the exact mode of activation (see above), it is further well documented - and not really surprising - that ACKR3 and CXCR4 induce a widely overlapping array of identical signaling molecules/pathways, including the ERK-, p38-, and phosphoinositide 3-kinase/AKT-signaling pathways (Wang et al., 2018a; Heuninck et al., 2019; Mousavi 2020, for recent reviews). Interestingly, the available data do not point to the existence of a general link between a given CXCL12 receptor and a distinct cellular response (at least in differentiated cells) in terms that one CXCL12 receptor controls cell migration, whereas the other one controls cell proliferation across various cell types. The findings rather argue for the cell-specific use of either CXCR4 or ACKR3 for controlling a given cellular function (Fig. 1B). Examples shown among others in Table 1 are the migration of melanocytes and decidual epithelial cells. Although (co)expressing both CXCL12 receptors, CXCL12-induced migration/chemotaxis of these cells depends on either ACKR3 or CXCR4, respectively (Lee et al., 2013; Zheng et al., 2018). Importantly, the differential use of either CXCR4 or ACKR3 to control a common cellular function likewise applies for tumor cells (see Table 1). This issue might be decisive for the therapeutical outcome of CXCR4 or ACKR3 antagonists applied to cancer patients.

We wish to note that we have deliberately not included studies in Table 1 in which the cellular function of CXCL12 was characterized by experimentally silencing either ACKR3 (see, for example, Wu et al., 2018) or CXCR4 (see, for example, Wang et al., 2018b). Although eligible, it is most evident that this experimental approach will not give an inherent view on the molecular function of the CXCL12 system in a given type of cells. This concern does not apply for studies in which the endogenous expression of either one of the CXCL12 receptors is not detectable (Luker et al., 2012).

It has been repeatedly argued that cell membrane expression (levels) of CXCR4 and ACKR3 would eventually determine which receptor mediates CXCL12 signaling. Especially ACKR3 was ruled out as the active CXCL12 receptor by many of these studies since in various cells the receptor protein prevails in intracellular structures, which was considered as a hint for its preferential interaction with CXCR4 (see, for example, Hartmann et al., 2008; Tripathi et al., 2014; Hsiao et al., 2015). In this respect, it is noteworthy that only a small portion of ACKR3 seems to cycle between the cell membrane and 
intracellular structures that might escape detection by immunofluorescence or cell sorting. In line with this view, Yan et al. (2012) demonstrated the crucial involvement of ACKR3 in the control of survival, adherence, and tube formation of human endothelial progenitor cells, although the receptor protein was almost exclusively detectable in intracellular structures by flow cytometry. Consequently, subcellular localization of CXCL12 receptors should be regarded as a rather poor indicator for their cellular use. An issue not yet experimentally tested is whether the differential use of CXCR4 and ACKR3 for controlling a common cell function in different types of cells is dictated by dimerization/oligomerization processes of either the ligand or the receptor itself. Indeed, secreted or soluble CXCL12 forms an equilibrium of monomers and dimers (Ray et al., 2012), which is modulated by several factors, such as pH and sulfate (Veldkamp et al., 2005). Monomeric CXCL12 seems to preferentially bind ACKR3 (Ray et al., 2012). Monomeric and dimeric CXCL12, on the other hand, exhibit distinct differences in their interaction with CXCR4, allowing for different signaling responses (Drury et al., 2011; Ray et al., 2012). This could explain why monomeric CXCL12 more potently stimulates chemotaxis than its dimeric form (Drury et al., 2011; Chang et al., 2017). Like its ligand, CXCR4 exists as monomers or homodimers, which both reside at the outer cell membrane as well as within intracellular structures (Wang et al., 2006). CXCR4 dimerization/oligomerization either depends on CXCL12 or occurs independently of the chemokine (see, for example, Ge et al., 2017; Lao et al., 2017;) and is further affected by CXCR4 expression levels (Lao et al., 2017). Interestingly, preventing CXCR4 dimerization abolishes CXCL12-induced chemotaxis of various cancer cell lines (Wang et al., 2006) and, thus, might represent a mechanism by which CXCR4 is either encompassed in or excluded from CXCL12 signaling. Further complexity of this process arises from recent demonstration that optimal CXCL12 responses require actin-dependent nanoclustering of CXCR4 (Martínez-Muñoz et al., 2018a). Although ACKR3 likewise exists as monomers and dimers (Levoye et al., 2009), currently no data are available as to whether the different status of the receptor protein is associated with functional differences. As documented for differentiating monocytes, another twist could stem from the fact that receptor signaling and, thus, affected cell function might depend on receptor protein levels. Actually, monocyte differentiation is accompanied by an upregulation of
ACKR3 and the subsequent switch from ERK and AKT signaling to activation of c-Jun N-terminal kinase and p38 pathways (Ma et al., 2013).

It has to be further kept in mind that in addition to homodimerization, heterodimerization of CXCR4 or ACKR3 with other non-CXCL12 chemokine receptors (MartínezMuñoz et al., 2018b); nonchemokine receptors, such as opioid receptors or adrenergic receptors (Nash and Meucci, 2014; Albee et al., 2017); or even nonreceptor proteins (Fumagalli et al., 2019) might contribute to the sculpting of CXCL12 signaling. (The role of CXCR4/ACKR3 heterodimers is discussed in the next chapter.) In this respect, previous work suggested that heterodimerization of CXCR4 with CXCR3 prolongs CXCR4 signaling (Jin et al., 2018). Other currently known modulators of CXCL12 signaling with the potency to impact the molecular organization of the CXCL12 system include regulators of $G$ protein signaling as well as $G$ protein-coupled receptor kinases (see, for example, Lipfert et al., 2013a; Karim et al., 2016; Saaber et al., 2019).

\section{Evidence that ACKR3 and CXCR4 Form a Functional Receptor in Distinct Cell Types}

An interesting observation made by several studies using either primary cells or tumor cells is that blockade of either CXCR4 or ACKR3 results in the complete loss of CXCL12dependent cellular responses (Table 2). These synergistic effects have been previously considered as an indication that CXCR4 and ACKR3 form a functional receptor complex in distinct cells (Lipfert et al., 2013b; Fig. 1C). In addition to homodimers, ACKR3 and CXCR4 equally form heterodimers (Levoye et al., 2009). Moreover, CXCR4/ACKR3 heterodimers seem to allow for enhanced recruitment of $\beta$-arrestin when compared with receptor monomers/homodimers resulting in the potentiation of $\beta$-arrestin-dependent cell signaling (Décaillot et al., 2011) and/or altered ERK-/AKT-phosphorylation kinetics (Del Molino del Barrio et al., 2018). However, despite these facts, it has not yet been tested whether the proposed functional CXCR4-ACKR3 receptor complex present in some cells actually involves receptor heterodimers. In this respect, it is noteworthy that combined fluorescence labeling of CXCR4 and ACKR3 in various tumor cell lines that require both CXCR4 and ACKR3 to respond to CXCL12 produced

TABLE 2

Cells proven to require both ACKR3 and CXCR4 to respond to CXCL12

\begin{tabular}{lll}
\hline Cell Type & \multicolumn{1}{c}{ Cell Function } & \multicolumn{1}{c}{ Reference } \\
\hline Human cervical cancer cell line (C33A) & Migration & Puchert et al., 2018 \\
Human breast adenocarcinoma cell line (MDA-MB-231) & Migration & $\begin{array}{c}\text { Yuchert et al., 2018; } \\
\text { Yang et al., 2019 }\end{array}$ \\
Human prostate adenocarcinoma cell line (PC-3) & Migration & $\begin{array}{c}\text { Puchert et al., 2018 } \\
\text { Melo et al., 2018 }\end{array}$ \\
Human acute myeloid leukemia cell line (U937) & Migration, homing & Huang et al., 2017 \\
Human endometrial cancer cell line (Ishikawa cells) & Proliferation & Long et al., 2016 \\
& Invasion & Chen et al., 2016 \\
Human oral squamous cell carcinoma cell lines & Migration & Qiao et al., 2016 \\
$\quad$ SCC15, CAL27) & Migration & Chen et al., 2015a \\
Human nasopharyngeal carcinoma cells & Migration & Chen et al., 2015b \\
Rat cardiac stem cells & Migration & Torossian et al., 2014 \\
Mouse neural progenitor cells & Proliferation & Lipfert et al., 2013b \\
Human peripheral blood CD34 cells & Migration, proliferation & Liu et al., 2013a \\
Rat primary microglia & Migration, proliferation & \\
Human glioblastoma cells (patient-derived) & &
\end{tabular}


TABLE 3

Cells in which CXCR4, ACKR3, and CXCR4/ACKR3 heterodimers control distinctly different cell functions

\begin{tabular}{|c|c|c|c|c|}
\hline Cell Type & CXCR4 & ACKR3 & CXCR4/ACKR3 & Reference \\
\hline Human monocytes & Migration & Adhesion, survival & $\begin{array}{l}\text { Phagocytic activity, cell } \\
\text { differentiation }\end{array}$ & Chatterjee et al., 2015 \\
\hline $\begin{array}{l}\text { Human adipose tissue-derived } \\
\text { mesenchymal stem cells }\end{array}$ & Migration & Proliferation & & Li et al., 2013 \\
\hline Human endothelial progenitor cells & $\begin{array}{l}\text { Migration, proliferation, } \\
\text { Nitric oxide production }\end{array}$ & Survival & $\begin{array}{l}\text { Transendothelial migration, } \\
\text { adhesion, tube formation }\end{array}$ & Yan et al., 2012 \\
\hline Mouse embryonic fibroblasts & Migration & Proliferation & & McGinn et al., 2012 \\
\hline Rat endothelial progenitor cells & Migration & Survival & $\begin{array}{l}\text { Transendothelial migration, } \\
\text { adhesion (on collagen and } \\
\text { fibronectin), tube formation, } \\
\text { proliferation }\end{array}$ & Dai et al., 2011 \\
\hline Human renal progenitor cells & Migration & Adhesion, survival & $\begin{array}{l}\text { Recruitment, transendothelial } \\
\text { migration }\end{array}$ & Mazzinghi et al., 2008 \\
\hline Human hematopoetic stem cells & Migration & & Adhesion & Hartmann et al., 2008 \\
\hline
\end{tabular}

rather inconclusive results. Specifically, these experiments showed overlapping CXCR4 and ACKR3 staining in distinct cellular domains, whereas other domains only showed staining for either CXCR4 or ACKR3 (Puchert et al., 2018). Finally, it has to be kept in mind that the requirement of CXCR4 and ACKR3 for CXCL12-dependent cellular responses does not necessarily reflect the involvement of CXCR4/ACKR3 heterodimers but could likewise be the result of converging downstream signaling events or the simultaneous activation of parallel signaling pathways.

Apart from the complete loss of CXCL12-induced cellular responses after blockade of either CXCR4 or ACKR3, few studies reported only partial losses of CXCL12-stimulated cell functions, hence implying that in some instances the cellular effects of CXCR4 and ACKR3 are additive (Fig. 1D). Additive effects have been reported for the transendothelial migration of mature CD14 ${ }^{+}-\mathrm{CD} 16^{+}$monocytes (Veenstra et al., 2017), migration of $\mathrm{T}$ lymphoblast (acute lymphoblastic leukemia) cell lines MOLT-4 and Jurcat (Melo et al., 2014), and tube formation of human umbilical vein endothelial cells (Zhang et al., 2017). The partial loss of cellular responses seen by these studies is not attributed to the incomplete blockade of receptor proteins since CXCR4 and ACKR3 antagonists (AMD3100, CCX771) were applied at effective concentrations $(2.5-10 \mu \mathrm{M})$. It is, however, hard to judge whether in studies using RNA interference (Melo et al., 2014) additive effects would arise from residual ACKR3 expression. Moreover, none of the studies excluded that additive effects are brought about by the presence of subpopulations of $\mathrm{CXCR}^{+}$, $\mathrm{ACKR3}^{+}$, and $\mathrm{CXCR}^{+} / \mathrm{ACKR}^{+}$cells. Whether existing additive effects result from the formation of CXCR4/ACKR3 heterodimers and subsequent potentiation of $\beta$-arrestin-dependent cell signaling (Décaillot et al., 2011) has not been experimentally tested.

\section{Within the Same Cell ACKR3 and CXCR4 Control Different Cell Functions}

Our current knowledge on the cellular effects of CXCR4 and ACKR3 culminate in the demonstration that within some cells, CXCR4, ACKR3, and/or CXCR4/ACKR3 heteromers are in the control of different cell functions (Fig. 1E; Table 3). Notably, the relation of distinct CXCL12 receptors to distinct cell functions has so far been mostly reported for various types of stem and progenitor cells. Specifically, the available studies (Table 3) demonstrate that stem/progenitor cell migration regularly depends on CXCR4 (Table 3) with only a few exemptions (Chen et al., 2015b). Provided parameters have been tested, and the studies further show that survival of stem/progenitor cells depends on ACKR3, whereas transendothelial migration instead requires both CXCR4 and ACKR3. This organizational concept is also partly documented for $\mathrm{CD}_{3} 4^{+}$hematopoetic stem cells, in which, again, CXCR4 controls cell migration, whereas CXCR4 in combination with ACKR3 affects cell adhesion (Hartmann et al., 2008). Whether this relation between receptors and cell functions applies to most stem/progenitor cells needs to be further evaluated. This future analysis should also include cancer stem cell, a clinically relevant subset of tumor cells that remains dormant, escapes chemotherapy, and hence gives rise to tumor relapse (Atashzar et al., 2020, for a recent review). Likewise, it is presently unknown whether the relation persists in differentiated cells or whether the CXCL12 system is rearranged during differentiation processes. The occurrence of a rearrangement process is currently favored by the observed heterogeneity of the CXCL12 system across different cells.

Importantly, in addition to stem and progenitor cells, distinct links between CXCL12 receptors and affected cell functions seem to be also realized, at least in some cancer cells. As previously shown (Puchert et al., 2018), CXCL12 controls proliferation of MDA-MB-231 breast cancer cells as well as PC-3 prostate cancer cells via CXCR4 whereas CXCL12dependent chemotaxis of both cell types requires ACKR3 and CXCR4 (Tables 1 and 2). Especially with respect to ongoing efforts to target CXCL12 receptors in cancer patients with receptor antibodies (Bobkov et al., 2019, for review) or receptor modulators (Adlere et al., 2019, for review), detailed knowledge of the organization of the CXCL12 system in distinct tumor cells emerges as a crucial prerequisite for successful therapy.

\section{ACKR3 as a Crosslinker of Different Receptor Systems}

As previously mentioned, additional recognized ligands for ACKR3 are CXCL11, MIF, ADM, bovine adrenal medulla 22, vCCL2/viral macrophage inflammatory protein-II, and opioid 
peptides. So far, active ACKR3 signaling has been shown to occur after binding of CXCL11 and MIF to ACKR3 but not of ADM, bovine adrenal medulla 22, vCCL2, and opioids, implying that ACKR3 might function as a scavenger for the latter ligands (Wang et al., 2018a; Meyrath et al., 2020, for review). Interestingly, CXCL11 binds CXCR3 as its prime receptor, which in turn forms heterodimers with CXCR4 and thus interweaves ACKR3 signaling with CXCR4 and CXCR3 signaling (Singh et al., 2013, for review). This meshwork gets further broadened by MIF, which, in addition to ACKR3, binds CD74, CXCR2, and CXCR4 (Wang et al., 2018a; PerpinaViciano et al., 2020). Moreover, CD74 heterodimerizes with ACKR3 (Alampour-Rajabi et al., 2015). Considering the intensive overlap of the various receptors, surprisingly little is known regarding whether and how the respective receptors modulate each other. As both a proof of principle and a hint to the complexity of these interactions, previous work demonstrated that CXCL11 attenuates CXCL12-dependent chemotaxis of of CT26 wild-type tumor cells (Rupertus et al., 2014) whereas pretreating HeLa cells with CXCL11 was found to facilitate CXCL12-induced chemotaxis (Miekus et al., 2010). Since ongoing work in our laboratory revealed that numerous cancer cells coexpress ACKR3, CXCR4, and CXCR3 (Puchert et al., 2018, 2020) a better understanding of these interactions is urgently needed.

\section{Concluding Remarks}

Findings on the function of ACKR3 obtained over the last decade reveal an unexpected heterogeneity of the molecular organization of the CXCL12 system across cells. In addition to its originally proposed silent function, it is now most evident that ACKR3 additionally acts as an active signaling receptor that, depending on the cell (type), either controls CXCL12dependent cell functions with similar efficacy as CXCR4 or interacts with CXCR4 in a fairly complex and diverse manner (Fig. 1). Although potential mechanisms capable of sculpting the cellular CXCL12 system, such as ligand and receptor dimerization/oligomerization, receptor heteromerization, regulators of $\mathrm{G}$ protein signaling, and $\mathrm{G}$ protein-coupled receptor kinases, emerged over recent years, the direct proof concerning whether and how these mechanisms dictate the molecular organization of the CXCL12 system in distinct cells still awaits experimental clarification. With the emerging role of ACKR3 and CXCR4 as therapeutic targets central to cancer, cardiovascular diseases, and inflammatory processes (Wang et al., 2018a; Morein et al., 2020; Mousavi, 2020), knowledge of these sculpting mechanisms is becoming more and more eminent, as they will allow for optimized therapeutic strategies. Finally, we hope that our present review will spark new interest into the function of ACKR3, which, as we feel, partially evaporated with its classification as an atypical chemokine receptor.

\section{Authorship Contributions}

Wrote or contributed to the writing of the manuscript: Koch, Engele.

\section{References}

Adlere I, Caspar B, Arimont M, Dekkers S, Visser K, Stuijt J, de Graaf C, Stocks M, Kellam B, Briddon S, et al. (2019) Modulators of CXCR4 and CXCR7/ACKR3 function. Mol Pharmacol 96:737-752 DOI: 10.1124/mol.119.117663.

Alampour-Rajabi S, El Bounkari O, Rot A, Müller-Newen G, Bachelerie F, Gawaz M, Weber C, Schober A, and Bernhagen J (2015) MIF interacts with CXCR7 to promote receptor internalization, ERK1/2 and ZAP-70 signaling, and lymphocyte chemotaxis. FASEB J 29:4497-4511 DOI: 10.1096/fj.15-273904.

Albee LJ, Eby JM, Tripathi A, LaPorte HM, Gao X, Volkman BF, Gaponenko V, and Majetschak M (2017) $\alpha_{1}$-Adrenergic receptors function within hetero-oligomeric complexes with atypical chemokine receptor 3 and chemokine (C-X-C motif) receptor 4 in vascular smooth muscle cells. $J$ Am Heart Assoc 6:e006575 DOI: 10.1161/ JAHA.117.006575.

Atashzar MR, Baharlou R, Karami J, Abdollahi H, Rezaei R, Pourramezan F, and Zoljalali Moghaddam SH (2020) Cancer stem cells: a review from origin to therapeutic implications. J Cell Physiol 235:790-803 DOI: 10.1002/ jcp.29044.

Bachelerie F, Ben-Baruch A, Burkhardt AM, Combadiere C, Farber JM, Graham GJ, Horuk R, Sparre-Ulrich AH, Locati M, Luster AD, et al. (2014) International Union of Basic and Clinical Pharmacology. [corrected]. LXXXIX. Update on the extended family of chemokine receptors and introducing a new nomenclature for atypical chemokine receptors. Pharmacol Rev 66:1-79.

Balabanian K, Lagane B, Infantino S, Chow KY, Harriague J, Moepps B, ArenzanaSeisdedos F, Thelen M, and Bachelerie F (2005) The chemokine SDF-1/CXCL12 binds to and signals through the orphan receptor RDC1 in T lymphocytes. J Biol Chem 280:35760-35766 DOI: 10.1074/jbc.M508234200.

Berahovich RD, Zabel BA, Lewén S, Walters MJ, Ebsworth K, Wang Y, Jaen JC, and Schall TJ (2014) Endothelial expression of CXCR7 and the regulation of systemic CXCL12 levels. Immunology 141:111-122 DOI: 10.1111/ imm. 12176 .

Bobkov V, Arimont M, Zarca A, De Groof TWM, van der Woning B, de Haard H, and Smit MJ (2019) Antibodies targeting chemokine receptors CXCR4 and ACKR3. Mol Pharmacol 96:753-764 DOI: 10.1124/mol.119.116954.

Burns JM, Summers BC, Wang Y, Melikian A, Berahovich R, Miao Z, Penfold ME, Sunshine MJ, Littman DR, Kuo CJ, et al. (2006) A novel chemokine receptor for SDF-1 and I-TAC involved in cell survival, cell adhesion, and tumor development. $J$ Exp Med 203:2201-2213 DOI: 10.1084/jem.20052144.

Cahill TJ III, Thomsen AR, Tarrasch JT, Plouffe B, Nguyen AH, Yang F, Huang LY, Kahsai AW, Bassoni DL, Gavino BJ, et al. (2017) Distinct conformations of GPCR$\beta$-arrestin complexes mediate desensitization, signaling, and endocytosis. Proc Natl Acad Sci USA 114:2562-2567 DOI: 10.1073/pnas.1701529114.

Chandrasekar B, Bysani S, and Mummidi S (2004) CXCL16 signals via Gi, phosphatidylinositol 3-kinase, Akt, I kappa B kinase, and nuclear factor-kappa B and induces cell-cell adhesion and aortic smooth muscle cell proliferation. J Biol Chem 279:3188-3196 DOI: $10.1074 /$ jbc.M311660200.

Chang HC, Huang PH, Syu FS, Hsieh CH, Chang SL, Lu J, and Chen HC (2018) Critical involvement of atypical chemokine receptor CXCR7 in allergic airway inflammation. Immunology 154:274-284 DOI: 10.1111/imm.12881.

Chang S, Li Y, Yuan F, Qu M, Song Y, Zhang Z, Yang GY, and Wang Y (2017) Monomeric CXCL12 outperforms its dimeric and wild type variants in the promotion of human endothelial progenitor cells' function [published correction appears in Biochem Biophys Res Commun (2018) 506:754]. Biochem Biophys Res Commun 488:303-310 DOI: 10.1016/j.bbrc.2017.03.172.

Chatterjee M, von Ungern-Sternberg SN, Seizer P, Schlegel F, Büttcher M, Sindhu NA, Müller S, Mack A, and Gawaz M (2015) Platelet-derived CXCL12 regulates monocyte function, survival, differentiation into macrophages and foam cells through differential involvement of CXCR4-CXCR7. Cell Death Dis 6:e1989 DOI: 10.1038/cddis.2015.233.

Chen D, Xia Y, Zuo K, Wang Y, Zhang S, Kuang D, Duan Y, Zhao X, and Wang G (2015a) Crosstalk between SDF-1/CXCR4 and SDF-1/CXCR7 in cardiac stem cell migration. Sci Rep 5:16813 DOI: 10.1038/srep16813.

Chen N, Jiang X, Wang J, Wu T, Cheng B, and Xia J (2016) CXCL12-CXCR4/CXCR7 axis contributes to cell motilities of oral squamous cell carcinoma. Tumour Biol 37: 567-575 DOI: 10.1007/s13277-015-3803-6.

Chen Q, Zhang M, Li Y, Xu D, Wang Y, Song A, Zhu B, Huang Y, and Zheng JC (2015b) CXCR7 mediates neural progenitor cells migration to CXCL12 independent of CXCR4. Stem Cells 33:2574-2585 DOI: 10.1002/stem.2022.

Choi YH, Burdick MD, Strieter BA, Mehrad B, and Strieter RM (2014) CXCR4, but not CXCR7, discriminates metastatic behavior in non-small cell lung cancer cells. Mol Cancer Res 12:38-47 DOI: 10.1158/1541-7786.MCR-12-0334.

Dai X, Tan Y, Cai S, Xiong X, Wang L, Ye Q, Yan X, Ma K, and Cai L (2011) The role of CXCR7 on the adhesion, proliferation and angiogenesis of endothelial progenitor cells. J Cell Mol Med 15:1299-1309 DOI: 10.1111/j.15824934.2011.01301.x.

Décaillot FM, Kazmi MA, Lin Y, Ray-Saha S, Sakmar TP, and Sachdev P (2011) CXCR7/CXCR4 heterodimer constitutively recruits beta-arrestin to enhance cell migration. J Biol Chem 286:32188-32197 DOI: 10.1074/jbc.M111.277038.

Del Molino Del Barrio I, Wilkins GC, Meeson A, Ali S, and Kirby JA (2018) Breast cancer: an examination of the potential of ACKR3 to modify the response of CXCR4 to CXCL12. Int J Mol Sci 19:3592 DOI: 10.3390/ijms19113592.

Doijen J, Van Loy T, De Haes W, Landuyt B, Luyten W, Schoofs L, and Schols D (2017) Signaling properties of the human chemokine receptors CXCR4 and CXCR7 by cellular electric impedance measurements. PLoS One 12:e0185354 DOI: 10.1371/journal.pone.0185354.

Donà E, Barry JD, Valentin G, Quirin C, Khmelinskii A, Kunze A, Durdu S, Newton LR, Fernandez-Minan A, Huber W, et al. (2013) Directional tissue migration through a self-generated chemokine gradient. Nature 503:285-289 DOI: 10.1038/ nature 12635

Drury LJ, Ziarek JJ, Gravel S, Veldkamp CT, Takekoshi T, Hwang ST, Heveker N, Volkman BF, and Dwinell MB (2011) Monomeric and dimeric CXCL12 inhibit metastasis through distinct CXCR4 interactions and signaling pathways. Proc Natl Acad Sci USA 108:17655-17660 DOI: 10.1073/pnas.1101133108.

Evans AE, Tripathi A, LaPorte HM, Brueggemann LI, Singh AK, Albee LJ, Byron KL, Tarasova NI, Volkman BF, Cho TY, et al. (2016) New insights into mechanisms and functions of chemokine (C-X-C motif) receptor 4 heteromerization in vascular smooth muscle. Int J Mol Sci 17:971 DOI: 10.3390/ ijms17060971. 
Fox JC, Thomas MA, Dishman AF, Larsen O, Nakayama T, Yoshie O, Rosenkilde MM, and Volkman BF (2019) Structure-function guided modeling of chemokineGPCR specificity for the chemokine XCL1 and its receptor XCR1. Sci Signal 12 eaat4128 DOI: $10.1126 /$ scisignal.aat4128.

Fumagalli A, Zarca A, Neves M, Caspar B, Hill SJ, Mayor F Jr, Smit MJ, and Marin P (2019) CXCR4/ACKR3 phosphorylation and recruitment of interacting proteins: key mechanisms regulating their functional status. Mol Pharmacol 96:794-808 DOI: $10.1124 / \mathrm{mol} .118 .115360$.

Ge B, Lao J, Li J, Chen Y, Song Y, and Huang F (2017) Single-molecule imaging reveals dimerization/oligomerization of CXCR4 on plasma membrane closely related to its function. Sci Rep 7:16873 DOI: 10.1038/s41598-017-16802-7.

Grundmann M, Merten N, Malfacini D, Inoue A, Preis P, Simon K, Rüttiger N, Ziegler N, Benkel T, Schmitt NK, et al. (2018) Lack of beta-arrestin signaling in the absence of active G proteins. Nat Commun 9:341 DOI: 10.1038/s41467-017-02661-

Haege S, Einer C, Thiele S, Mueller W, Nietzsche S, Lupp A, Mackay F, Schulz S, and Stumm R (2012) CXC chemokine receptor 7 (CXCR7) regulates CXCR4 protein expression and capillary tuft development in mouse kidney. PLoS One 7:e42814 DOI: 10.1371/journal.pone.0042814.

Hartmann TN, Grabovsky V, Pasvolsky R, Shulman Z, Buss EC, Spiegel A, Nagler A Lapidot T, Thelen M, and Alon R (2008) A crosstalk between intracellular CXCR7 and CXCR4 involved in rapid CXCL12-triggered integrin activation but not in chemokine-triggered motility of human T lymphocytes and CD34+ cells. J Leukoc Biol 84:1130-1140 DOI: 10.1189/jlb.0208088.

Heuninck J, Perpiñá Viciano C, I'bilir A, Caspar B, Capoferri D, Briddon SJ, Durroux T, Hill SJ, Lohse MJ, Milligan G, et al. (2019) Context-dependent signaling of CXC chemokine receptor 4 and atypical chemokine receptor 3. Mol Pharmacol 96: 778-793 DOI: 10.1124/mol.118.115477.

Hsiao JJ, Ng BH, Smits MM, Wang J, Jasavala RJ, Martinez HD, Lee J, Alston JJ, Misonou H, Trimmer JS, et al. (2015) Androgen receptor and chemokine receptor 4 and 7 form a signaling axis to regulate CXCL12-dependent cellular motility. BMC Cancer 15:204 DOI: 10.1186/s12885-015-1201-5.

Huang Y, Ye Y, Long P, Zhao S, Zhang L, and Yanni A (2017) Silencing of CXCR4 and CXCR7 expression by RNA interference suppresses human endometrial carcinoma growth in vivo. Am J Transl Res 9:1896-1904.

Jin J, Zhang Z, Wang H, Zhan Y, Li G, Yang H, Fei Z, Xu Y, and Li W (2018) CXCR3 expression in colorectal cancer cells enhanced invasion through preventing CXCR4 internalization. Exp Cell Res 371:162-174 DOI: 10.1016/ j.yexcr.2018.08.006

Jin J, Zhao WC, and Yuan F (2013) CXCR7/CXCR4/CXCL12 axis regulates the proliferation, migration, survival and tube formation of choroid-retinal endothelia cells. Ophthalmic Res 50:6-12 DOI: 10.1159/000348532.

Karim ZA, Alshbool FZ, Vemana HP, Conlon C, Druey KM, and Khasawneh FT (2016) CXCL12 regulates platelet activation via the regulator of G-protein signaling 16. Biochim Biophys Acta 1863:314-321 DOI: 10.1016/ j.bbamcr.2015.11.028

Kim HY, Lee SY, Kim DY, Moon JY, Choi YS, Song IC, Lee HJ, Yun HJ, Kim S, and Jo DY (2015) Expression and functional roles of the chemokine receptor CXCR7 in acute myeloid leukemia cells. Blood Res 50:218-226 DOI: $10.5045 /$ br.2015.50.4.218

Kobayashi K, Sato K, Kida T, Omori K, Hori M, Ozaki H, and Murata T (2014) Stromal cell-derived factor-1 $\alpha / \mathrm{C}-\mathrm{X}-\mathrm{C}$ chemokine receptor type 4 axis promotes endothelial cell barrier integrity via phosphoinositide 3-kinase and Rac1 activation. Arterioscler Thromb Vasc Biol 34:1716-1722 1722 DOI: 10.1161/ ATVBAHA.114.303890

Koenen J, Bachelerie F, Balabanian K, Schlecht-Louf G, and Gallego C (2019) Atypical chemokine receptor 3 (ACKR3): a comprehensive overview of its expression and potential roles in the immune system. Mol Pharmacol 96:809-818 DOI $10.1124 / \mathrm{mol} .118 .115329$

Lao J, He H, Wang X, Wang Z, Song Y, Yang B, Ullahkhan N, Ge B, and Huang F (2017) Single-Molecule imaging demonstrates ligand regulation of the oligomeric status of CXCR4 in living cells. J Phys Chem B 121:1466-1474 DOI: 10.1021/ acs.jpcb.6b10969.

Lau S, Feitzinger A, Venkiteswaran G, Wang J, Lewellis SW, Koplinski CA, Peterson FC, Volkman BF, Meier-Schellersheim M, and Knaut H (2020) A negative-feedback loop maintains optimal chemokine concentrations for directional cell migration. Nat Cell Biol 22:266-273 DOI: 10.1038/s41556-020-0465-4.

Lee E, Han J, Kim K, Choi H, Cho EG, and Lee TR (2013) CXCR7 mediates SDF1induced melanocyte migration. Pigment Cell Melanoma Res 26:58-66 DOI: $10.1111 / \mathrm{pcmr} .12024$

Levoye A, Balabanian K, Baleux F, Bachelerie F, and Lagane B (2009) CXCR7 heterodimerizes with CXCR4 and regulates CXCL12-mediated G protein signaling. Blood 113:6085-6093 DOI: 10.1182/blood-2008-12-196618

Li Q, Zhang A, Tao C, Li X, and Jin P (2013) The role of SDF-1-CXCR4/CXCR7 axis in biological behaviors of adipose tissue-derived mesenchymal stem cells in vitro. Biochem Biophys Res Commun 441:675-680 DOI: 10.1016 j.bbrc. 2013.10 .071

Lipfert J, Ödemis V, and Engele J (2013a) Grk2 is an essential regulator of CXCR7 signalling in astrocytes. Cell Mol Neurobiol 33:111-118 DOI: 10.1007/s10571-012 9876-5

Lipfert J, Ödemis V, Wagner DC, Boltze J, and Engele J (2013b) CXCR4 and CXCR7 form a functional receptor unit for SDF-1/CXCL12 in primary rodent microglia. Neuropathol Appl Neurobiol 39:667-680 DOI: 10.1111/nan.12015.

Liu C, Pham K, Luo D, Reynolds BA, Hothi P, Foltz G, and Harrison JK (2013a) Expression and functional heterogeneity of chemokine receptors CXCR4 and CXCR7 in primary patient-derived glioblastoma cells. PLoS One 8:e59750 DOI 10.1371/journal.pone.0059750.

Liu S, Jia X, Li C, Han X, Yan W, and Xing Y (2013b) CXCR7 silencing attenuates cell adaptive response to stromal cell derived factor $1 \alpha$ after hypoxia. PLoS One 8 e55290 DOI: 10.1371 /journal.pone.0055290.
Long P, Sun F, Ma Y, and Huang Y (2016) Inhibition of CXCR4 and CXCR7 for reduction of cell proliferation and invasion in human endometrial cancer. Tumour Biol 37:7473-7480 DOI: 10.1007/s13277-015-4580-y.

Luker KE, Gupta M, Steele JM, Foerster BR, and Luker GD (2009) Imaging liganddependent activation of CXCR7. Neoplasia 11:1022-1035 DOI: 10.1593/neo.09724.

Luker KE, Lewin SA, Mihalko LA, Schmidt BT, Winkler JS, Coggins NL, Thomas DG, and Luker GD (2012) Scavenging of CXCL12 by CXCR7 promotes tumor growth and metastasis of CXCR4-positive breast cancer cells. Oncogene 31: 4750-4758 DOI: 10.1038/onc.2011.633.

Luo J, Busillo JM, Stumm R, and Benovic JLG (2017) G protein-coupled receptor kinase 3 and protein kinase $\mathrm{C}$ phosphorylate the distal $\mathrm{C}$-terminal tail of the chemokine receptor CXCR4 and mediate recruitment of $\beta$-arrestin. Mol Pharmacol 91:554-566 DOI: 10.1124/mol.116.106468.

Luttrell LM, Wang J, Plouffe B, Smith JS, Yamani L, Kaur S, Jean-Charles P-Y, Gauthier C, Lee M-H, Pani B, et al. (2018) Manifold roles of $\beta$-arrestins in GPCR signaling elucidated with siRNA and CRISPR/Cas9. Sci Signal 11:eaat7650 DOI: 10.1126/scisignal.aat7650.

Ma W, Liu Y, Ellison N, and Shen J (2013) Induction of C-X-C chemokine receptor type 7 (CXCR7) switches stromal cell-derived factor-1 (SDF-1) signaling and phagocytic activity in macrophages linked to atherosclerosis. J Biol Chem 288: 15481-15494 DOI: 10.1074/jbc.M112.445510.y.

Martínez-Muñoz L, Rodríguez-Frade JM, Barroso R, Sorzano CÓS, Torreño-Pina JA, Santiago CA, Manzo C, Lucas P, García-Cuesta EM, Gutierrez E, et al. (2018a) Separating actin-dependent chemokine receptor nanoclustering from dimerization indicates a role for clustering in CXCR4 signaling and function [published correction appears in Mol Cell (2018) 71:873]. Mol Cell 70:106-119.e10 DOI: 10.1016/ j.molcel.2018.02.034

Martínez-Muñoz L, Villares R, Rodríguez-Fernández JL, Rodríguez-Frade JM, and Mellado M (2018b) Remodeling our concept of chemokine receptor function: from monomers to oligomers. J Leukoc Biol 104:323-331 DOI: 10.1002/JLB.2MR1217-503R

Mazzinghi B, Ronconi E, Lazzeri E, Sagrinati C, Ballerini L, Angelotti ML, Parente E, Mancina R, Netti GS, Becherucci F, et al. (2008) Essential but differential role for CXCR4 and CXCR7 in the therapeutic homing of human renal progenitor cells. J Exp Med 205:479-490 DOI: 10.1084/jem.20071903.

McGinn OJ, Marinov G, Sawan S, and Stern PL (2012) CXCL12 receptor preference, signal transduction, biological response and the expression of 5T4 oncofoetal glycoprotein. J Cell Sci 125:5467-5478 DOI: 10.1242/jcs.109488.

Melo RCC, Ferro KPV, Duarte ADSS, and Olalla Saad ST (2018) CXCR7 participates in CXCL12-mediated migration and homing of leukemic and normal hematopoietic cells. Stem Cell Res Ther 9:34 DOI: 10.1186/s13287-017-0765-1.

Melo RCC, Longhini AL, Bigarella CL, Baratti MO, Traina F, Favaro P, de Melo Campos P, and Saad ST (2014) CXCR7 is highly expressed in acute lymphoblastic leukemia and potentiates CXCR4 response to CXCL12. PLoS One 9:e85926 DOI: 10.1371/journal.pone.0085926.

Meyrath M, Szpakowska M, Zeiner J, Massotte L, Merz MP, Benkel T, Simon K, Ohnmacht J, Turner JD, Krüger R, et al. (2020) The atypical chemokine receptor ACKR3/CXCR7 is a broad-spectrum scavenger for opioid peptides. Nat Commun 11:3033 DOI: $10.1038 / \mathrm{s} 41467-020-16664-0$.

Miekus K, Jarocha D, Trzyna E, and Majka M (2010) Role of I-TAC-binding receptors CXCR3 and CXCR7 in proliferation, activation of intracellular signaling pathways and migration of various tumor cell lines. Folia Histochem Cytobiol 48:104-111 DOI: $10.2478 / \mathrm{v} 10042-008-0091-7$.

Min K, Yoon HJ, Park JY, Baidya M, Dwivedi-Agnihotri H, Maharana J, Chaturvedi M, Chung KY, Shukla AK, and Lee HH (2020) Crystal structure of $\beta$-arrestin 2 in complex with CXCR7 phosphopeptide. Structure S0969-2126;30205-30207 DOI: 10.1016/j.str.2020.06.002

Morein D, Erlichman N, and Ben-Baruch A (2020) Beyond cell motility: the expanding roles of chemokines and their receptors in malignancy. Front Immunol 11:952 DOI: $10.3389 /$ fimmu.2020.00952.

Mousavi A (2020) CXCL12/CXCR4 signal transduction in diseases and its molecular approaches in targeted-therapy. Immunol Lett 217:91-115 DOI: 10.1016/ j.imlet.2019.11.007.

Nash B and Meucci O (2014) Functions of the chemokine receptor CXCR4 in the central nervous system and its regulation by $\mu$-opioid receptors. Int Rev Neurobiol 118:105-128 DOI: 10.1016/B978-0-12-801284-0.00005-1.

Ödemis V, Boosmann K, Heinen A, Küry P, and Engele J (2010) CXCR7 is an active component of SDF-1 signalling in astrocytes and Schwann cells. J Cell Sci 123: 1081-1088 DOI: $10.1242 /$ jes.062810.

Ödemis V, Lipfert J, Kraft R, Hajek P, Abraham G, Hattermann K, Mentlein R, and Engele J (2012) The presumed atypical chemokine receptor CXCR7 signals through $\mathrm{G}(\mathrm{i} / \mathrm{o})$ proteins in primary rodent astrocytes and human glioma cells. Glia 60:372-381 DOI: 10.1002/glia.22271.

Perpina-Viciano C, Isbilir A, Zarca A, Caspar B, Kilpatrick LE, Hill SJ, Smit MJ, Lohse MJ, and Hoffmann C (2020) Kinetic analysis of the early signaling steps of the human chemokine receptor CXCR4. Mol Pharmacol 98:72-87 DOI: 10.1124/ mol.119.118448.

Puchert M, Koch C, and Engele J (2018) The 5T4 oncofetal glycoprotein does not act as a general organizer of the CXCL12 system in cancer cells. Exp Cell Res 364 175-183 DOI: 10.1016/j.yexcr.2018.02.001.

Puchert M, Obst J, Koch C, Zieger K, and Engele J (2020) CXCL11 promotes tumor progression by the biased use of the chemokine receptors CXCR3 and CXCR7. Cytokine 125:154809 DOI: 10.1016/j.cyto.2019.154809.

Puchert M, Pelkner F, Stein G, Angelov DN, Boltze J, Wagner DC, Odoardi F, Flüge A Streit WJ, and Engele J (2017) Astrocytic expression of the CXCL12 receptor, CXCR7/ACKR3 is a hallmark of the diseased, but not developing CNS. Mol Cell Neurosci 85:105-118 DOI: 10.1016/j.mcn.2017.09.001.

Qiao N, Wang L, Wang T, and Li H (2016) Inflammatory CXCL12-CXCR4/CXCR7 axis mediates G-protein signaling pathway to influence the invasion and migration of nasopharyngeal carcinoma cells. Tumour Biol 37:8169-8179 DOI: 10.1007/ s13277-015-4686-2. 
Quinn KE, Mackie DI, and Caron KM (2018) Emerging roles of atypical chemokine receptor 3 (ACKR3) in normal development and physiology. Cytokine 109:17-23 DOI: $10.1016 /$ j.cyto.2018.02.024.

Rajagopal S, Kim J, Ahn S, Craig S, Lam CM, Gerard NP, Gerard C, and Lefkowitz RJ (2010) Beta-arrestin- but not G protein-mediated signaling by the "decoy" receptor CXCR7. Proc Natl Acad Sci USA 107:628-632 DOI: 10.1073/pnas.0912852107.

Ray P, Lewin SA, Mihalko LA, Lesher-Perez SC, Takayama S, Luker KE, and Luker GD (2012) Secreted CXCL12 (SDF-1) forms dimers under physiological conditions. Biochem J 442:433-442 DOI: 10.1042/BJ20111341.

Rigo A, Ferrarini I, Innamorati G, and Vinante F (2018) A single amino acid substitution in CXCL12 confers functional selectivity at the beta-arrestin level. Oncotarget 9:28830-28841 DOI: 10.18632/oncotarget.25533.

Romain B, Hachet-Haas M, Rohr S, Brigand C, Galzi JL, Gaub MP, Pencreach E, and Guenot D (2014) Hypoxia differentially regulated CXCR4 and CXCR7 signaling in colon cancer. Mol Cancer 13:58 DOI: 10.1186/1476-4598-13-58.

Rupertus K, Sinistra J, Scheuer C, Nickels RM, Schilling MK, Menger MD, and Kollmar O (2014) Interaction of the chemokines I-TAC (CXCL11) and SDF-1 (CXCL12) in the regulation of tumor angiogenesis of colorectal cancer. Clin Exp Metastasis 31:447-459 DOI: 10.1007/s10585-014-9639-4.

Saaber F, Schütz D, Miess E, Abe P, Desikan S, Ashok Kumar P, Balk S, Huang K, Beaulieu JM, Schulz S, et al. (2019) ACKR3 regulation of neuronal migration requires ACKR3 phosphorylation, but not $\beta$-arrestin. Cell Rep 26:1473-1488.e9 DOI: 10.1016/j.celrep.2019.01.049.

Salazar N, Muñoz D, Kallifatidis G, Singh RK, Jordà M, and Lokeshwar BL (2014) The chemokine receptor CXCR7 interacts with EGFR to promote breast cancer cell proliferation. Mol Cancer 13:198 DOI: 10.1186/1476-4598-13-198.

Sánchez-Alcañiz JA, Haege S, Mueller W, Pla R, Mackay F, Schulz S, López-Bendito G, Stumm R, and Marín O (2011) Cxcr7 controls neuronal migration by regulating chemokine responsiveness. Neuron 69:77-90 DOI: 10.1016/j.neuron.2010.12.006.

Singh AK, Arya RK, Trivedi AK, Sanyal S, Baral R, Dormond O, Briscoe DM, and Datta D (2013) Chemokine receptor trio: CXCR3, CXCR4 and CXCR7 crosstalk via CXCL11 and CXCL12. Cytokine Growth Factor Rev 24:41-49 DOI: 10.1016/ j.cytogfr.2012.08.007.

Thomsen ARB, Jensen DD, Hicks GA, and Bunnett NW (2018) Therapeutic targeting of endosomal G-protein-coupled receptors. Trends Pharmacol Sci 39:879-891 DOI: 10.1016/j.tips.2018.08.003.

Thomsen ARB, Plouffe B, Cahill TJ III, Shukla AK, Tarrasch JT, Dosey AM, Kahsai AW, Strachan RT, Pani B, Mahoney JP, et al. (2016) GPCR-G protein- $\beta$-arrestin super-complex mediates sustained G protein signaling. Cell 166:907-919 DOI: 10.1016/j.cell.2016.07.004.

Torossian F, Anginot A, Chabanon A, Clay D, Guerton B, Desterke C, Boutin L, Marullo S, Scott MG, Lataillade JJ, et al. (2014) CXCR7 participates in CXCL12induced CD34+ cell cycling through $\beta$-arrestin-dependent Akt activation. Blood 123:191-202 DOI: 10.1182/blood-2013-05-500496.

Tripathi A, Davis JD, Staren DM, Volkman BF, and Majetschak M (2014) CXC chemokine receptor 4 signaling upon co-activation with stromal cell-derived factor$1 \alpha$ and ubiquitin. Cytokine 65:121-125 DOI: 10.1016/j.cyto.2013.12.008.

Veenstra M, Williams DW, Calderon TM, Anastos K, Morgello S, and Berman JW (2017) Frontline Science: CXCR7 mediates CD $14^{+} \mathrm{CD} 16^{+}$monocyte transmigration across the blood brain barrier: a potential therapeutic target for NeuroAIDS. $J$ Leukoc Biol 102:1173-1185 DOI: 10.1189/jlb.3HI0517-167R.

Veldkamp CT, Peterson FC, Pelzek AJ, and Volkman BF (2005) The monomer-dimer equilibrium of stromal cell-derived factor-1 (CXCL 12) is altered by $\mathrm{pH}$, phosphate, sulfate, and heparin. Protein Sci 14:1071-1081 DOI: 10.1110/ps.041219505.

Wang C, Chen W, and Shen J (2018a) CXCR7 targeting and its major disease relevance. Front Pharmacol 9:641 DOI: 10.3389/fphar.2018.00641.
Wang J, He L, Combs CA, Roderiquez G, and Norcross MA (2006) Dimerization of CXCR4 in living malignant cells: control of cell migration by a synthetic peptide that reduces homologous CXCR4 interactions. Mol Cancer Ther 5:2474-2483 2483 DOI: 10.1158/1535-7163.MCT-05-0261.

Wang X, Wang H, Wei X, Wang A, Wen L, Wang L, and Huang Q (2018b) Effect of CXCR4 silencing with shRNA on MAPK signaling in ovarian cancer. Oncol Lett 15: 10026-10030 DOI: 10.3892/ol.2018.8550.

Wang Y, Xu P, Qiu L, Zhang M, Huang Y, and Zheng JC (2016) CXCR7 participates in CXCL12-mediated cell cycle and proliferation regulation in mouse neural progenitor cells. Curr Mol Med 16:738-746 DOI: 10.2174/ 1566524016666160829153453

Wu Y, Tian L, Xu Y, Zhang M, Xiang S, Zhao J, and Wang Z (2018) CXCR7 silencing inhibits the migration and invasion of human tumor endothelial cells derived from hepatocellular carcinoma by suppressing STAT3. Mol Med Rep 18: $1644-1650$

Xu S, Tang J, Wang C, Liu J, Fu Y, and Luo Y (2019) CXCR7 promotes melanoma tumorigenesis via Src kinase signaling. Cell Death Dis 10:191 10.1038/s41419-019$1442-3$

Yan X, Cai S, Xiong X, Sun W, Dai X, Chen S, Ye Q, Song Z, Jiang Q, and Xu Z (2012) Chemokine receptor CXCR7 mediates human endothelial progenitor cells survival, angiogenesis, but not proliferation. J Cell Biochem 113:1437-1446 DOI: 10.1002/ jcb.24015.

Yang M, Zeng C, Li P, Qian L, Ding B, Huang L, Li G, Jiang H, Gong N, and Wu W (2019) Impact of CXCR4 and CXCR7 knockout by CRISPR/Cas9 on the function of triple-negative breast cancer cells. OncoTargets Ther 12:3849-3858 DOI: 10.2147/ OTT.S195661.

Yu L, Pham Q, Yu LL, and Wang TTY (2020) Modulation of CXC-motif chemokine receptor 7 , but not 4, expression is related to migration of the human prostate cancer cell LNCaP: regulation by androgen and inflammatory stimuli. Inflamm Res 69:167-178 DOI: 10.1007/s00011-019-01305-0.

Zabel BA, Lewén S, Berahovich RD, Jaén JC, and Schall TJ (2011) The novel chemokine receptor CXCR7 regulates trans-endothelial migration of cancer cells. Mol Cancer 10:73 DOI: 10.1186/1476-4598-10-73.

Zhang J, Zhang Y, Xin S, Wu M, Zhang Y, and Sun L (2020) CXCR7 suppression modulates macrophage phenotype and function to ameliorate post-myocardial infarction injury. Inflamm Res 69:523-532 DOI: 10.1007/ s00011-020-01335-z.

Zhang M, Qiu L, Zhang Y, Xu D, Zheng JC, and Jiang L (2017) CXCL12 enhances angiogenesis through CXCR7 activation in human umbilical vein endothelial cells. Sci Rep 7:8289 DOI: 10.1038/s41598-017-08840-y.

Zhang S, Hong Z, Li Q, Lei J, Huang H, and Liu Q (2016) Effect of MicroRNA-218 on the viability, apoptosis and invasion of renal cell carcinoma cells under hypoxia by targeted downregulation of CXCR7 expression. Biomed Pharmacother 80:213-219 DOI: 10.1016/j.biopha.2016.03.011.

Zheng J, Wang H, and Zhou W (2018) Modulatory effects of trophoblast-secreted CXCL12 on the migration and invasion of human first-trimester decidual epithelial cells are mediated by CXCR4 rather than CXCR7. Reprod Biol Endocrinol 16:17 DOI: 10.1186/s12958-018-0333-2.

Zlotnik A and Yoshie O (2012) The chemokine superfamily revisited. Immunity 36: 705-716 DOI: 10.1016/j.immuni.2012.05.008.

Address correspondence to: Dr. Jürgen Engele, Institute of Anatomy, University of Leipzig, Medical Faculty, Liebigstr. 13, 04103 Leipzig, Germany. E-mail: engj@medizin.uni-leipzig.de 